\title{
The role of the IL-33-ST2 axis in the pathogenesis of periodontitis
}

\author{
0 papel do eixo IL-33-ST2 na patogênese \\ da periodontite
}

\author{
Mabel Proence Pereira Lopes' ${ }^{1}$ (1) \\ Paulo Cirino de Carvalho-Filho ${ }^{2}$ (1) \\ Ellen Karla Nobre dos Santos-Lima ${ }^{3}$ (1) \\ Rebeca Pereira Bulhosa Santos 4 (1) \\ Isaac Suzart Gomes-Filho ${ }^{5}$ (i) \\ Soraya Castro Trindade ${ }^{6}$ (i)
}

1,3,4Universidade Federal da Bahia (Salvador). Bahia, Brasil. mabelpronece@gmail.com, ellenobre@hotmail.com, biorebecabulhosa@gmail.com Universidade Federal da Bahia (Salvador), Escola Bahiana de Medicina e Saúde Pública (Salvador). Bahia, Brasil. pauloccfilho@gmail.com ${ }^{5}$ Universidade Estadual de Feira de Santana (Feira de Santana). Bahia, Brasil. isuzart@gmail.com ${ }^{6}$ Corresponding author. Universidade Estadual de Feira de Santana (Feira de Santana), Universidade Federal da Bahia (Salvador). Bahia, Brasil. soraya@uefs.br

\begin{abstract}
INTRODUCTION: Periodontitis is a chronic inflammatory disease that arises from an interaction of local dysbiosis in the subgingival biofilm and the host immune response. The disease triggers an inflammatory process that can cause periodontal tissue breakdown. In addition, the production of inflammatory mediators can negatively affect other areas of the body and influence the development and/or severity of associated disorders, including asthma, diabetes and cardiovascular diseases. OBJECTIVE: Conduct a literature review to comprehensively investigate the role of ST2 and IL-33 and the contribution of the IL-33 / ST2 axis in the pathogenesis of periodontitis. METHODS: It is a narrative literature review, which used the databases Pubmed and Academic Google with a total of 114 results. RESULTS: A range of immunological markers has been shown to be relevant in the immunopathogenesis of periodontitis, like cytokines of the interleukin 1 (IL-1) family, such as IL-1 $\beta$ and IL-33. IL-33, through its ST2 receptor, appears to be involved in the development of periodontitis, acting as a molecule that signals tissue damage from infection and also emits an endogenous signal that activates the immune response and / or worsens bone resorption by activating osteoclastogenesis, in a manner dependent or not on RANKL. CONCLUSION: The diversity of the methodologies of these studies hampers attempts to standardize and make correlations between published data, in this sense, the IL-33 / ST2 axis remains a relevant topic in investigations focused on the diagnosis and treatment of periodontal disease.
\end{abstract}

KEYWORDS: Periodontal disease. Immune response. Cytokines. Dysbiosis.
RESUMO | INTRODUÇÃO: A periodontite é uma doença inflamatória crônica que surge de uma interação entre a disbiose local no biofilme subgengival e a resposta imune do hospedeiro. A doença desencadeia um processo inflamatório que pode causar ruptura do tecido periodontal. Além disso, a produção de mediadores inflamatórios pode afetar negativamente outras áreas do corpo e influenciar o desenvolvimento e / ou gravidade de distúrbios associados, incluindo asma, diabetes e doenças cardiovasculares. OBJETIVO: Realizar uma revisão da literatura para investigar o papel de ST2 e IL-33 e a contribuição do eixo IL-33 / ST2 na patogênese da periodontite. MÉTODOS: Trata-se de uma revisão narrativa da literatura, que utilizou as bases de dados Pubmed e Academic Google em um total de 114 resultados. RESULTADOS: Uma gama de marcadores imunológicos têm se mostrado relevante na imunopatogênese da periodontite, como citocinas da família da interleucina 1 (IL-1), IL-1 $\beta$ e IL-33. A IL-33, por meio de seu receptor ST2, parece estar envolvida no desenvolvimento da periodontite, atuando como uma molécula que sinaliza o dano tecidual da infecção e também emite um sinal endógeno que ativa a resposta imune e / ou piora a reabsorção óssea pela ativação da osteoclastogênese, tanto por aumentos em RANK-L como por redução de OPG, ou independentemente dessa via. CONCLUSÃO: A diversidade de metodologias desses estudos dificulta tentativas de padronização e correlações entre os dados publicados, nesse sentido, o eixo IL-33 / ST2 continua sendo um tema relevante nas investigações voltadas para o diagnóstico e tratamento da doença periodontal.

PALAVRAS-CHAVE: Doença periodontal. Resposta imune. Citocinas. Disbiose. 


\section{Introduction}

Periodontal diseases are one of the most prevalent inflammatory diseases found in humans. Periodontal diseases can be seen in up to $90 \%$ of the global population ${ }^{1}$, being the most common oral disease. It has been estimated that just $17.8 \%$ of the Brazilian adult population, aged between 35 and 44 years, has no periodontal disease. Gingivitis and periodontitis are among the most common periodontal diseases, while gingivitis is an inflammatory process that only affects the soft tissues around the teeth, periodontitis also affects supporting tissues. Periodontitis, an inflammatory, chronic, multifactorial disease occurring in periodontal tissue characterized by the progressive destruction of periodontal tissues (gingiva, alveolar bone and periodontal ligament), initiates from the presence of biofilm in the subgingival region?2. This arises from an imbalance between the microbiota and the host immune response, which triggers a dysbiotic process, which has the ability to modulate the host's response in a way that impairs immune surveillance and alters the balance, homeostasis ${ }^{3}$.

Microorganisms present in the subgingival biofilm, such as Porphyromonas gingivalis, Treponema denticola, Tannerella forsythia and Prevotella intermedia, may elicit an immune response in the host that can lead to serious systemic effects ${ }^{4}$. Previous studies have pointed to the impact of periodontal infection on systemic conditions, including cardiovascular disease, cerebrovascular accidents ${ }^{5}$, preterm birthand and low neonatal birthweight ${ }^{6}$, in addition to diabetes ${ }^{7}$, asthma and pneumonia ${ }^{\circ}$.

One of the more widely accepted biological mechanisms linking this oral disease with systemic conditions is the production of inflammatory markers. Several markers have been determined to play relevant roles in the development and/or progression of periodontitis, such as interleukin- 6 (IL6), tumoral necrosis factor (TNF) and IL-1 $\beta$. Others, such as IL-33, an interleukin of the IL-1 $\beta$ family, and its receptor, ST2, have been poorly investigated. The participation of the IL-33/ST2 axis was recently shown to play an important role in the immunopathogenesis of periodontitis ${ }^{10}$.

IL-33 can act as an immune system alarmin (alarm signal) when released by damaged cells, which in turn activates other cells expressing the ST 2 receptor. This can induce the release and production of inflammatory cytokines and may activate osteoclastogenesis, either dependently, or independently, of the RANK/ RANKL pathway. However, this process requires further investigation ${ }^{10}$.

Gene ST2, originally abbreviated as "serum STimulation-2" has come to be known as "suppression of tumorigenicity 2," IL-1RL1, IL-33R or T1. The suppressive effect of this gene was identified at the beginning of the growth cycle of quiescent BALB/c3T3 cells, while also simultaneously promoting the growth of cells during cellular division. At the time, the ST2 ligand had not been identified ${ }^{11}$.

It was later suggested that the ST2 gene encodes type I transmembrane protein ST2L (serum STimulation-2 large), which bears a sequence quite similar to that of the interleukin-1 receptor type I (IL-1RL1). Following this discovery, investigations began to focus on the immunological aspects of ST2. IL-33 was soon after identified as a member of the IL-1 family, and has been described as the only ligand to ST2 ${ }^{12}$. 
IL-33 is considered to be a damage-associated molecular pattern (DAMP), as it is released by fibroblasts, macrophages and/or endothelial and epithelial cells in response to cellular injury or infection. IL-33 can also induce the activation of Th2 cells, which then produce IL-5 and IL-13, in addition to promoting the migration of neutrophils in an ST2dependent manner. In eosinophils, this cytokine may induce degranulation, as well as the production of oxygen reactive species (ROS) and IL-5 secretion. In mastocytes, it promotes the release of IL-4, IL-5 and IL6 , while developing an M2 phenotype in macrophages. In contrast, IL-33 may induce the release of cytokines, such as IFN-y and TNF, involved in inflammatory processes and diseases such as asthma, allergies, cardiovascular disease, inflammatory intestinal disorders, diabetes and periodontitis ${ }^{13}$.

Accordingly, the present study aimed to review the role of IL-33, its ST2 receptor and the IL-33/ST2 axis in an attempt to elucidate the influence of these mediators within the context of the pathogenesis of periodontitis.

\section{Methods}

It is a narrative literature review, which used the databases Pubmed and Academic Google. The search was carried out in March 2018 and the free search strategy was defined, using the descriptors: "IL33 and periodontal disease", "IL33 and periodontitis", "ST2 and periodontal disease", "ST2 and periodontitis". The inclusion criteria applied were: scientific articles published in the last twenty years, addressing the proposed topic, in Portuguese, English and Spanish. The following criteria were used to exclude articles: articles that were not related to the proposed theme, repeated articles and in languages other than English,
Portuguese and Spanish. The search revealed a total of 114 results: 43 found in google academic and 71 found in PubMed, with 43 duplicates. Finally, 43 articles were selected in accordance with the inclusion and exclusion criteria, based on the title and abstract. All selected articles are written in the English language

\section{Results}

\section{The ST2 Receptor}

The ST2 receptor was considered na orphan for many years until IL-33 was identified as the specific ligand of membrane-anchored ST2- ST2L12. Due to its structural characteristics, especially the presence of the intracytoplasmic domain known as Toll/interleukin-1 receptor (TIR), this receptor was also classified as a member of the IL-1 receptor superfamily. In addition, its molecular structure contains an extracellular domain that binds to IL-33 with the aid of Interleukin 1 Receptor Accessory Protein (IL-1RAP) ${ }^{14}$.

In general, after binding to IL-33, ST2L forms a heterodimer with IL-1RAP14 leading to the dimerization of the TIR domain. This intracellular signaling cascade then proceeds to recruit MyD88, the ligand protein of the TIR domain, and later activates the kinase associated with IL-1R (IRAK) and TNF receptor-associated factor 6 (TRAF6). Activated IRAK and TRAF6 can thusly phosphorylate nuclear factor kappa B (NF-KB) or Activator protein 1 (AP-1). The ST2/ IL-33 signaling pathway may culminate either by way of the activation of AP-1 (through mitogen-activated protein kinases - MAPK), or NF-kB. However, previous investigations focused on this topic were unable to clarify this phenomenon, yet did establish that the activation of both transcription factors leads to the production of inflammatory cytokines ${ }^{15}$. 
Figure 1. The ST2/IL-33 signaling pathway

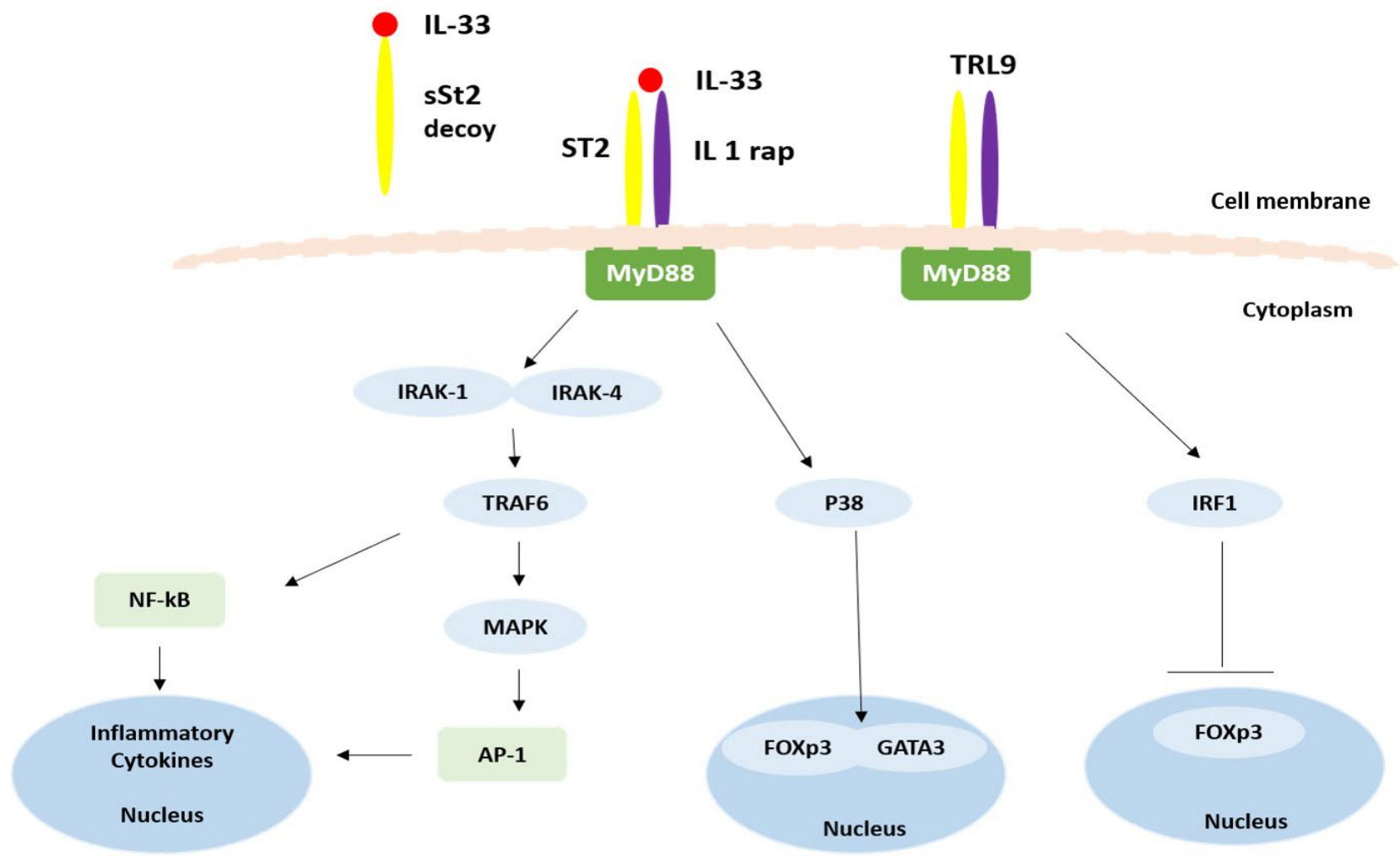

Source: Adapted from GRIESENAUER and PACZESNY (2017). After the binding of IL-33 with ST2 / IL-1, a heterodimer is formed with IL 1RAP that will recruit MyD88, the TIR domain binding protein, and later activate the IL-1R-associated kinase (IRAK) and factor 6 associated with the TNF receptor (TRAF6). Activated IRAK and TRAF6 will phosphorylate nuclear factor kappa B (NF-kB) or Activator protein 1 (AP-1). The ST2 / IL-33 signaling pathway can be through the activation of AP-1 (through mitogen-activated protein kinases - MAPK) or NF-kB. The activation of both transcription factors leads to the production of inflammatory cytokines

In regulatory T-cells (Treg), the ST2/IL-33 axis can promote the expression of a member of the forkhead family of protein transcription factors (Foxp3) and the ligand GATA3 while simultaneously promoting the proliferation of Treg cells mediated by transforming growth factor (TGF- $\beta 1$ ) by way of a mechanism dependent on the P38 protein. Since this effect is observed in Tregs in a microenvironment independent of external inflammatory responses, it is believed the that ST2/IL-33-GATA3-Foxp3 pathway is canonical. On the other hand, in a non-canonical MyD88dependent pathway signaling by the IFN type-1 regulatory factor (IRF) can inhibit the activation of Tregs by way of binding to the Foxp3 promotor, which interrupts the transcription of Foxp3 in T cells, thusly favoring the inflammatory response ${ }^{16}$.

It was initially suggested that ST2L was correlated with the Th2-mediated immune response, since this ligand is preferentially expressed in murine and human Th2 cells regardless of stimulation by cytokines, e.g. IL-4, IL-5 e IL-10, yet this expression is supposedly absent in Th1 cells. However, it is now known that this receptor is also expressed by a variety of other cells, including Th1 cells, B lymphocytes, neutrophils, monocytes, mastocytes, dendritic cells, basophils, eosinophils, natural killer (NK) cells, NK T cells (NKT), type 2 innate lymphoid cells (ILC2) and Tregs ${ }^{17}$.

Additional research has demonstrated that the ST2 gene also produces, via alternative splicing, a secreted protein form with an extracellular domain identical to that of ST2L, soluble ST2 (ST2s) (HAYAKAWA H, et al., 2007) and two variant forms: ST2V (variant) and ST2LV (large variant). ST2V is expressed in leukemic human cells and is highly expressed in gastrointestinal organs ST2LV is secreted by tissues in the eyes, heart, lungs and liver, and is present during posterior development of embryogenesis ${ }^{18}$. 
The soluble form of the protein, ST2s, is not known to trigger an intracellular cascade, but is capable of binding to soluble IL-33, which prevents this cytokine from interacting with the ST2L receptor, thereby blocking the effects generated by this interaction ${ }^{19}$. It is in this context that soluble ST2 has been described as an antagonist receptor against the effects of IL-3320 as it modulates the participation of this cytokine in the inflammatory process.

In humans, ST2s may be spontaneously produced not only by cells in the lungs, kidneys, heart and small intestine, but also by mastocytes activated by IL-33. ST2s production is increased in epithelial cells of the human lung and cardiac myocytes under stimulation by cytokines such as IL-1 $\beta$ and TNF. In addition, increased levels of ST2s may inhibit the production of cytokines, such as IL- 4 and IL-5, in contrast to what is observed in cytokines IFN-y and IL-2 21 .

Elevated serum levels of ST2s have been reported, as well as in other body fluids, in individuals who suffer from a variety of disorders, such as bronchial asthma, systemic lupus erythematosus, acute eosinophilic pneumonia, celiac disease, idiopathic pulmonary fibrosis, malignant pleural effusion, subarachnoid hemorrhage, HIV progression and acute myocardial infarction 22 .

It is impossible to explain the wide spectrum of diseases in which elevated levels of ST2s are present in the serum or other body fluids as simply the result of the immunologic functioning of proteins coded by the ST2 gene. Although still in need of clarification, it seems that ST2-produced proteins influence cellular proliferation, growth and migration via a pathway independent of IL-33 binding, which has been demonstrated in both malignant cells and also in a strain of murine fibroblasts ${ }^{23}$.

\section{The Interleukin 33}

IL-33 was firstly identified as a protein present in the high endothelial venules (HEV) of the tonsils, Peyer's plaques and lymph nodes, being described as a "nuclear factor of the high endothelial venules" (NF-HEV). It is now known that IL-33 can act as an extracellular ligand or as an intracellular signaling molecule, accordingly, this protein's characteristics are unconventional in the interleukin family.
For instance, while IL-33 is not actively secreted by cells $^{24}$ it reaches the extracellular environment by cellular injury or death.

Extracellular IL-33 plays a role in the coordination of immunological defense and repair mechanisms. Intracelular IL-33 participates in the regulation of gene expression as a nuclear protein, in addition to functioning as a molecule, known as "alarmin", that recognizes cellular damage. To this end, IL-33 accumulates in the nuclei of cells and is released following stress or damage arising from cellular or tissue injury, infection or necrosis. In these situations, IL-33 acts as an alarmin, it alerts the immunological system to the presence of trauma or infection. The term alarmin pertains to endogenous molecules that emit this type of signal, such as those belonging to the family of DAMPs - damage-associated molecular patterns ${ }^{25}$.

Since it is constitutively expressed in the cellular nucleus, IL-33 is immediately available for release into the extracellular environment after damage. This protein is also present in a range of immune cells, e.g. monocytes/macrophages and dendritic cells, and non-immune cells, such as fibroblasts, adipocytes, epithelial cells, endothelial cells, smooth muscle cells and salivary gland cells, as well as in a variety of tissues, including stomach, lung, spinal medulla, cerebral and $\operatorname{skin}^{26}$.

When secreted, this cytokine is capable of activating cells possessing the ST2 receptor, such as basophils, mastocyes, eosinophils, type 2 innate lymphoid cells (ILC2), Th2 lymphocytes and Tregs ${ }^{27}$.

It is also known that IL-33, in spite of its full-length activation undergoes cleavages in its original form. Cleavage by inflammatory proteases generates mature forms that significantly increase the activity of this cytokine. The mature forms generated by neutrophil and mastocyte proteases may be the principal bioactive forms of IL-33 in diseased tissues ${ }^{28}$. It has been demonstrated that IL-331-270 undergoes proteolytic cleavage by cathepsin $\mathrm{G}$ and neutrophilderived elastase, which produces the following peptides: IL-3395-270, IL-3399-270 and IL-33109-270, all of which present greater biological activity than their precursor IL-331-270. It is interesting to note that after IL-33 undergoes the proteolytic cleavage, it is unable to translocate to the nucleus ${ }^{29}$. 
As IL-33 is a cytokine with multiple functions, its action varies in accordance with the type of stimulus encountered. It can function as a transcription factor due to some of its structural characteristics, such as a nuclear localization sequence in the $\mathrm{N}$-terminal domain and a homeodomain containing a helixturn-helix motif, where the IL-33-containing domains overlap with high local concentrations of DNA, indicating association of endogenous IL-33 with heterochromatin, thus, it is capable of binding to heterochromatin in the nucleus of endothelial cells in vivo and can exert a regulatory transcriptional function that remains poorly understood 30 .

When tissue damage is accompanied by infiltrating or commensal microorganisms, as occurs in the intestinal epithelium, the action of IL-33 becomes mediated by the induction of IFN-Y and TNF. This occurs when antigen-presenting cells (APC) activated by pathogen-associated molecular patterns (PAMP) secrete IL-12 and IL-23. IL-12 increases ST2 expression in $\mathrm{T}$ and NK cells, which, when bound to IL-33, forms the IL-33/ST2 axis, inducing increases in IFN-Y and TNF. It is important to note the inflammatory process is accompanied by a regulatory process. Accordingly, elevated levels of IFN-y and TNF can promote the secretion of an IL-33 antagonist, soluble ST2, with respect to IL-23, this cytokine neutralizes IL-33 signaling in Treg ST2+ cells and can limit the proliferating capability of IL-33 in Treg ST2+ cells ${ }^{31}$ thereby contributing to the exacerbation of the inflammatory response.

As in all pathways of immune response induction, as the etiological agent becomes controlled, negative feedback mechanisms are activated to return the involved tissues to equilibrium. Accordingly, once PAMPs and/or pathogens are eliminated, IL-33 production at the site of infection initiates a reparative tissue process via ILC2 and Treg. IL-33 signaling in $\mathrm{T}$ cells stimulates the Treg response both initially, by enhancing Treg cell differentiation mediated by TGF- $\beta 1$, and later by providing the necessary signaling to maintain Treg cells at the sites of inflammation ${ }^{32}$.

In allergic or parasitic processes, IL-33 stimulates cells, such as basophils, mastocytes, ILC2s and Th2 lymphocytes to produce IL-5, IL-13, chemokines and proteins that act as chemo attractants for eosinophils26. While these cells mediate parasite elimination, the chronic activation of this pathway can cause allergic disease and tissue fibrosis. Under these conditions, IL-33 stimulates myeloid cells to secrete IL-2, which synergizes with IL-33 to stimulation the expansion of ST2+ Treg cells ${ }^{33}$.

ST2+ Treg cells, present in the primary and secondary lymphoid tissues, adipose tissue, the lungs and intestine, stimulate immunological regulatory function and the tissue repair process in response to IL-33 by way of cellular proliferation and the expression of amphiregulin epidermal growth factor (AREG). IL-33 is also capable of activating ILC2, which aids in tissue repair through the production of AREG and the differentiation of $\mathrm{M} 2$ macrophages ${ }^{28}$.

As previously mentioned, IL-33 acts not only on tissue regulation and repair mechanisms but may also participate in inflammation. In sum, IL-33 may be involved in the triggering of inflammatory processes through the induction of IFN- $y$, TNF, IL- 6 and IL-1 $\beta$ expression or by interfering in the activation of Treg, ILC2 or M2 macrophage cells ${ }^{28}$.

It is interesting to note that the action of IL-33 is regulated by several mechanisms: the retention of this cytokine in the nuclei of IL-33-producing cells during homeostasis the cleavage of domains similar to IL-1 by caspases during apoptosis, through the sequestration of IL-33 by soluble ST2 protein, through the action of single Ig IL1R-related (SIGIRR) molecule in the formation of dimers with ST2L, by the oxidation of cysteine residues and the formation of disulfide (SS) bridges in IL-33 after extracellular release ${ }^{34}$.

Finally, the participation of the IL-33/ST2 axis has already been described in the immunopathogenesis of several disorders, such as cardiovascular disease, asthma, atopic dermatitis, inflammatory bowel disease, systemic erythematosus lupus, allergic rhinitis, chronic obstructive pulmonary disease and chronic colitis as well as in destructive inflammatory disorders, such as rheumatoid arthritis and periodontitis ${ }^{35}$. 
Periodontitis is a disease with an etiology consisting of multiple bacteria, that trigger a range of immunoinflammatory events, leading to tooth loss. While it is more prevalent in adults, this disease can also beset children and adolescents. The degree of tissue destruction is generally proportional to the presence of biofilm, intensity of host response related risk factors, It has been demonstrated that elevated levels of production and expression of IL-33 and its ST2L receptor are present in tissues and gingival epithelial cells in both mice and humans ${ }^{36}$ providing further evidence of the role of the IL-33/ST2 axis in the pathogenesis of periodontitis.

IL-33 can be involved in the pathogenesis of periodontitis by way of several mechanisms (Figure 2). This cytokine can act as an alarminat the moment of periodontal tissue damage, exacerbating local or systemic inflammatory processes through the activation of immune cells to secrete cytokines by way of the activation of the IL-33/ST2 axis and/or through the induction of osteoclastogenesis ${ }^{37}$.

Figure 2. Role of IL-33 in the immunopathogenesis of periodontitis

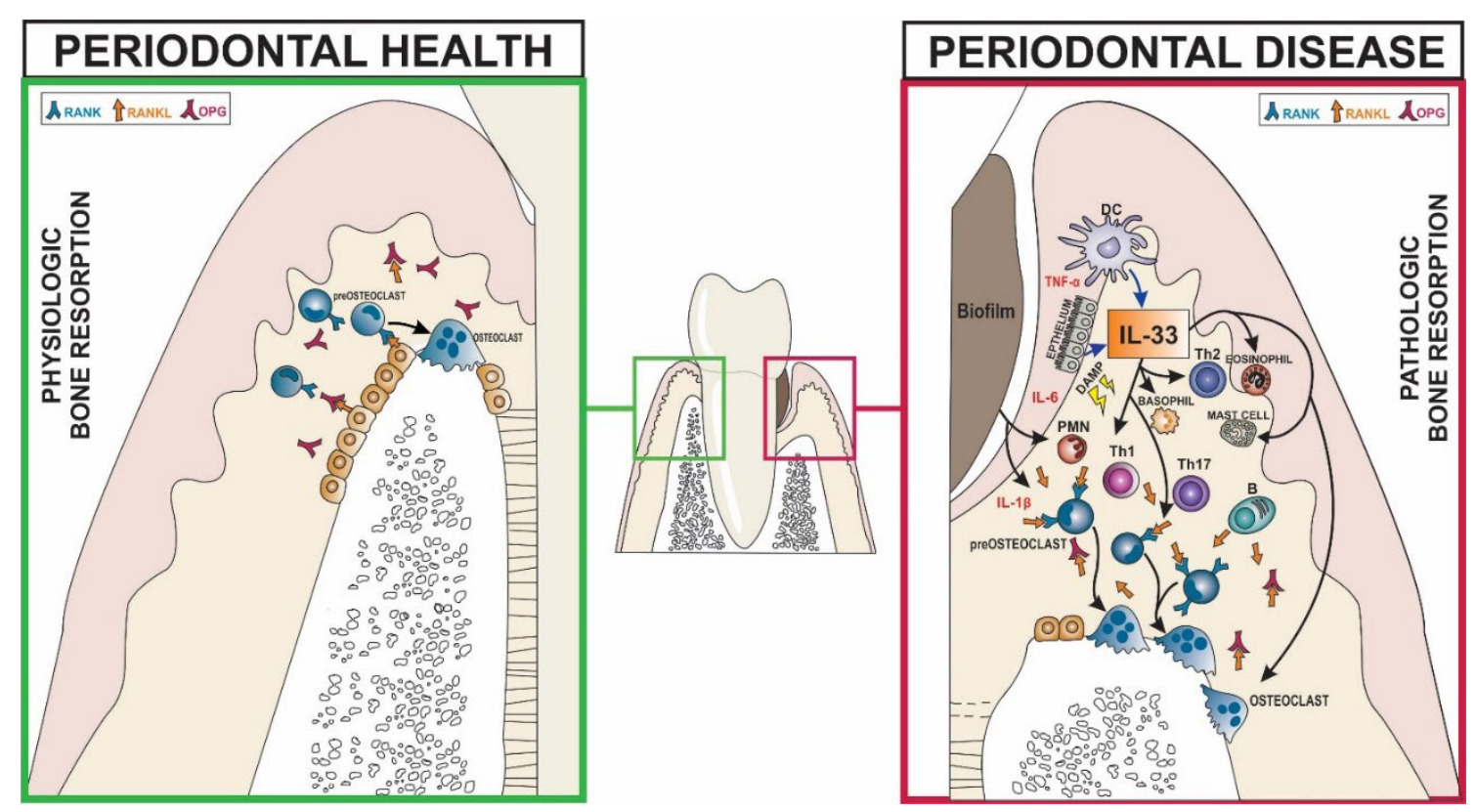

Source: Author himself. Left: Representation of physiological bone resorption of periodontal tissues in the absence of periodontitis. Among other factors, bone resorption and formation are regulated by relative concentrations of RANKL (expressed by a variety of cells, including osteoblasts), the RANK receptor in pre-osteoclasts and the soluble receptor OPG. The binding of RANKL to the pre-osteoclast induces its differentiation into multinucleated cells that become mature osteoclasts. When OPG concentrations are relatively higher than RANKL expression, OPG binds to RANKL, thereby inhibiting the binding of this molecule to RANK, leading to reduced osteoclast formation (osteoclastogenesis) and to the apoptosis of pre-osteoclasts. Right: Representation of bone resorption in periodontal tissues when periodontal pathogens colonize the oral microenvironment, inducing local dysbiosis, inflammatory reactions and cellular damage in surrounding tissues. When cells are damaged, IL-33 is released by epithelial cells and fibroblasts, acting as alarmin (DAMP) that signals immune system activation. Immunological cells, such as polymorphonuclear neutrophils (PMN), B cells (B), dendritic cells (DC) and T cells (Th1, Th2 and Th17) are recruited to the site of inflammation. The production of cytokines (TNF, IL-1b, IL- 6 and IL-33) becomes increased in the microenvironment, enhancing the expression of RANKL by osteoclasts. IL-33 is constitutively expressed by dendritic cells and the monocytes. Activated T cells also secrete soluble RANKL and TNF, which induces the release of IL-33 in lysed gingival fibroblasts. Once released, IL-33 is capable of activating cells, such as basophils, mastocytes, eosinophils, innate type 2 lymphoid cells (ILC2), Th2 lymphocytes and Tregs, in addition to increasing the production of RANKL and decreasing the production of OPG, thus favoring RANK-RANKL interaction. Periodontal pathogens can also induce the expression of IL-33 and RANKL, which contributes to increased osteoclastogenesis and, consequently,

alveolar bone loss. In addition, IL-33 can directly bind to its receptor, ST2, in the osteoclasts and activate these cells. This activation, differently than the abovementioned RANK/RANKL mechanism, occurs via the IL-22/ST2 axis. 
It is believed that proinflammatory cytokine levels become elevated due to infectious bacterial processes $^{37}$. Keystone pathogens present in the dysbiotic biofilm, such as Porphyromonas gingivalis, can induce the expression of IL-33 in human gingival and oral epithelial cells by way of gingipainsdependent mechanisms. In dendritic murine cells, TLR2-mediated IL-33 expression primarily increases in response to stimulation with fimbriae and lipopeptides derived from P. gingivalis. Immature dendritic cells, such as Langerhans cells, are known to infiltrate the gingival epithelium of individuals with gingivitis or periodontitis. These findings suggest that the gingival epithelium represents an important source of IL-33 production following infection by periodontal pathogens and that IL-33 can modulate the function of dendritic cells in the context of periodontal disease ${ }^{38}$.

Of the diverse cells activated by the IL-33/ST2 axis, Th2 lymphocytes and, in particular, mastocytes exert relevant roles in the pathogenesis of periodontitis. Th2 lymphocytes are important in later stages of periodontitis, as these cells produce IL-4, IL-5 and IL-13 cytokines. Mastocytes are present in all tissue types, immediately recognize IL-33 and are readily capable of inducing an inflammatory response ${ }^{39}$. IL33 can promote mastocyte survival, maturation and maintenance, as well as initiate the expression of chemokines, IL-6, IL-1 $\beta$ TNF and lipid mediators.

TNF has been implicated as a powerful inducer of IL-33 production in lysed gingival fibroblasts, acting as an alarmin for this cytokine. As previously mentioned, following the elimination of pathogenic agents, IL-33 exerts a regulatory and repairing effect on periodontal tissue by inducing the production of cytokines, such as IL-4, IL-5, IL-6, IL-10 e IL-13. In addition, inflammatory cytokines present in the gingival fluid of individuals with periodontitis may stimulate the production of RANKL, a protein known to be crucial to osteoclastogenesis ${ }^{40}$.

Alveolar bone loss is a characteristic sign of periodontitis. Osteoclastogenesis mediated by the activating receptor of NF-kB (RANK) and its ligand (RANKL) is essential to the bone resorption process. RANK is expressed on the surfaces of osteoclasts, while RANKL is expressed on the surfaces of osteoblasts. During binding, osteoclastic precursor differentiation and activation signaling becomes activated, inducing the bone resorption observed in periodontitis. Osteoprotegerin (OPG) is a soluble receptor that, when bound to RANKL, impedes this ligand's interaction with RANK and is capable of antagonizing the effects of binding, thereby preserving bone integrity. However, the role of IL-33 in the induction of RANKL production as well as the reduction of OPG production must be noted, since this activity favors the RANK/RANKL interaction that activates osteoclastogenesis and consequent alveolar bone loss (Figure 2) ) $^{41}$.

In mice infected with P. gingivalis, treatment with IL-33 significantly increased alveolar bone loss, with attenuated alveolar loss observed in mice knocked out for ST2. In addition, increased IL-33 expression was demonstrated in human and mouse models of periodontitis ${ }^{10}$. Furthermore, it was shown that both $P$. gingivalis and IL-33 were able to independently induce RANKL expression, further emphasizing the relevant role of IL-33 in the pathogenesis of periodontitis, studies have shown that overexpression of IL-33 in gingival epithelial cells is associated with periodontitis and can trigger the expression of RANK-L, in addition to the direct effect of P. gingivalis, therefore, IL-33 can act as an extracellular alarm, showing properties pro-inflammatory in periodontitis, perpetuating bone resorption induced by P. gingivalis infection ${ }^{36}$.

IL-33 was also demonstrated to stimulate osteoclast differentiation in vitro by way of increasing the production of osteoclast transcription factors. This activation occurs via the bonding of IL-33 to the ST2 receptor, regardless of the activation of the RANK/ RANKL axis, which differs from the mechanism described in the previous paragraph ${ }^{42}$.

It was further observed that the total amount of IL-33 detected in gingival fluid seemed to be greater in individuals with periodontitis, in addition to being positively correlated with gingival and plaque index clinical parameters ${ }^{10}$. However, this was not the case with IL-33 levels in saliva and plasma, since no variations were observed between individuals with or without periodontitis or gingivitis in comparison to healthy individuals, although, without statistical relevance, IL-33 levels were higher in clinically healthy patients. This could be explained by IL-33 levels below the detection range of the quantification method employed, or, simply, due to a lack of association with periodontitis ${ }^{43}$. 
Although few studies have demonstrated a relationship between the presence of the IL-33/ ST2 axis and the pathogenesis of periodontitis, this warrants further investigation.

\section{Conclusion}

The pleiotropic cytokine IL-33 is capable of eliciting action from a diverse range of cell types, both those of innate immunity and adaptive response, through binding with ST2. Although the IL-33/ST2 axis may be involved in the development of a variety of diseases through the release of inflammatory mediators, it can also perform relevant functions in the regulatory and tissue repair phases. In the pathogenesis of periodontitis, the role played by this axis in osteoclastogenesis and the consequent exacerbation of bone loss, in a manner dependent or not on RANKL, is notable. In addition, IL-33 can function as a DAMP, as well as a cytokine that activates cells, such as mastocytes and Th2 lymphocytes. Previous studies on IL-33 have classified periodontitis differently, and employed the collection of dissimilar samples. The diversity of these studies' methodologies hampers attempts to standardize and make correlations among the published data, which consequently hinders our ability to draw conclusions regarding the role of the IL-33/ST2 axis in periodontitis. Accordingly, the IL-33/ST2 axis remains a relevant topic in investigations focused on the diagnosis and treatment of periodontal disease.

\section{Acknowledgments and financing}

The authors would like to thank the Post-graduate Immunology Program (PPGIm) of Federal University of Bahia (UFBA), the Immunology and Molecular Biology Laboratory of UFBA (LABIMUNO), the ProAr Foundation, and the Center for Research and Integrated Practice and Multidisciplinary Investigation (NUPPIIM) of the Feira de Santana State University (UEFS).The authors are also grateful to Andris K. Walter for English language revision and manuscript copyediting assistance. The authors are also grateful to Michelle Falcao, Patrícia Mares, Marcia Tosta and Roberto Meyer. This study was funded by Research Support Foundation of the State of Bahia (FAPESB), by Research and Extension Support Foundation (FAPEX) and by Research for the SUS Program (PPSUS).

\section{Author contributions}

Lopes MPP drafted and developed the review. Carvalho-Filho PC, Santos-Lima EKN, Santos RPB, Gomes-Filho IS participated in writing and in the critical review. Trindade SC participated in writing and in the critical review and supervised the research.

\section{Competing interests}

No financial, legal or political competing interests with third parties (government, commercial, private foundation, etc.) were disclosed for any aspect of the submitted work (including but not limited to grants, data monitoring board, study design, manuscript preparation, statistical analysis, etc.).

\section{References}

1. Nazir MA. Prevalence of periodontal disease, its association with systemic diseases and prevention. Int J Health Sci. 2017;11(2):72-80.

2. Papapanou PN, Sanz M, Baduneli N, Dietrich T, Feres M, Fine DH et al. Periodontitis: Consensus report of workgroup 2 of the 2017 World Workshop on the Classification of Periodontal and PeriImplant Diseases and Conditions. J Clin Periodontol. 2018;45:162170. http://dx.doi.org/10.1111/jcpe.12946

3. Pace CC, Mccullough GH. The association between oral microorgansims and aspiration pneumonia in the institutionalized elderly: review and recommendations. Dysphagia. 2010;25(4):30722. http://dx.doi.org/10.1007/s00455-010-9298-9

4. Scannapieco FA, Dasanayake AP, Chhun N. "Does periodontal therapy reduce the risk for systemic diseases?". Dent Clin North Am. 2010;54(1):163-81. http://dx.doi.org/10.1016/j. cden.2009.10.002

5. Joshipura KJ, Hung HC, Rimm EB, Willett WC, Ascherio A. Periodontal disease, tooth loss, and incidence of ischemic stroke. Stroke. 2003;34(1):47-52. http://dx.doi.org/10.1161/01. str.0000052974.79428.0c

6. Gomes-Filho IS, Pereira EC, Cruz SS, Adan LFF, Vianna MIP, Passos-Soares JS et al. Relationship Among Mothers' Glycemic Level, Periodontitis, and Birth Weight. J Periodontol. 2016,87(3):238-47. http://dx.doi.org/10.1902/jop.2015.150423

7. Genco RJ, Grossi AG, Ho A, Nishimura F, Murayama Y. A proposed model linking inflammation to obesity, diabetes, and periodontal infections. J Periodontol. 2005;76(11 Suppl):2075-84. http://dx.doi.org/10.1902/jop.2005.76.11-S.2075 
8. Gomes-Filho IS, Oliveira TFL, Passos-Soares JS, Trindade SC, Oliveira MT, Souza-Machado A et al. Influence of periodontitis in the development of nosocomial pneumonia: a case control study. J Periodontol. 2014;85(5):e82-90. http://dx.doi.org/10.1902/ jop.2013.130369

9. Trindade S, Olczak T, Gomes-Filho IS, Moura-Costa LF, Vale VC, Galdino Neto $\mathrm{M}$ et al. Porphyromonas gingivalis HmuY-Induced Production of Interleukin- 6 and IL-6 Polymorphism in Chronic Periodontitis. J Periodontol. 2013;84(5):650-655. http://dx.doi. org/10.1902/jop.2012.120230

10. Sağlam M, Köseoğlu S, Aral CA, Savran L, Pekbağrıyanık T, Çetinkaya A. Increased levels of interleukin-33 in gingival crevicular fluids of patients with chronic periodontitis. Odontology. 2017;105(2):184-190. http://dx.doi.org/10.1007/ s10266-016-0259-0

11. Tominaga S. A putative protein of a growth specific CDNA from BALB/c-3T3 cells is highly similar to the extracellular portion of mouse interleukin 1 receptor. FEBS Lett. 1989;258(2):301-4. http://dx.doi.org/10.1016/0014-5793(89)81679-5

12. Schmitz J, Owyang A, Oldham E, Song Y, Murphy E, McClanahan TK et al. IL-33, an interleukin-1-like cytokine that signals via the IL-1 receptor-related protein ST2 and induces T helper type 2-associated cytokines. Immunity. 2005;23(5):479-90 http://dx.doi.org/10.1016/j.immuni.2005.09.015

13. Gungor O, Unal HU, Guclu A, Gezer M, Eyileten T, Guzel FB et al. IL-33 and ST2 levels in chronic kidney disease: Associations with inflammation, vascular abnormalities, cardiovascular events, and survival. PLoS One. 2017;12(6): e0178939. http://dx.doi. org/10.1371/journal.pone.0178939

14. Chackerian AA, Oldham ER, Murphy EE, Schmitz J, Pflanz S, Kastelein RA. IL-1 receptor accessory protein and ST2 comprise the IL-33 receptor complex. J Immunol. 2007;179(4):2551-5. http:// dx.doi.org/10.4049/jimmunol.179.4.2551

15. Griesenauer B, Paczesny S. The ST2/IL-33 Axis in Immune Cells during Inflammatory Diseases. Front Immunol. 2017;(8):475. http://dx.doi.org/10.3389/fimmu.2017.00475

16. Gabriele L, Stellacci E, Borghi P, Perrotti E, Ilari R, Lanciotti A et al. IFN regulatory factor- 1 negatively regulates $C D 4+C D 25+$ regulatory $\mathrm{T}$ cell differentiation by repressing Foxp3 expression. J Immunol. 2008;181(3):1673-82. http://dx.doi.org/10.4049/ jimmunol.181.3.1673

17. Bonilla WV, Fröhlich A, Helmstetter C, Peine M, Hegazy AN, Pinschewer DD et al. T-bet- and STAT4-dependent IL-33 receptor expression directly promotes antiviral Th1 cell responses. Proc Natl Acad Sci. 2015; 112(13): 4056-61. http://dx.doi.org/10.1073/ pnas. 1418549112
18. Iwahana H, Hayakawa M, Kuroiwa K, Tago K, Yanagisawa $\mathrm{K}$, Noji S et al. Molecular cloning of the chicken ST2 gene and a novel variant form of the ST2 gene product, ST2LV. Biochim Biophys Acta. 2004;1681(1):1-14. http://dx.doi.org/10.1016/j. bbaexp.2004.08.013

19. Hayakawa H, Hayakawa M, Kume A, Tominaga SI. Soluble ST2 blocks interleukin-33 signaling in allergic airway inflammation. J Biol Chem. 2007;282(36):26369-80. http://dx.doi.org/10.1074/jbc. M704916200

20. Jiang HR, Milovanović M, Allan D, Niedbala W, Besnard AG, Fukada SY et al. IL-33 attenuates EAE by suppressing IL-17 and IFN-gamma production and inducing alternatively activated macrophages. Eur J Immunol, 2012;42(7):1804-14. http://dx.doi. org/10.1002/eji.201141947

21. Oshikawa K, Yanagisawa K, Tominaga S, Sugiyama Y et al. Expression and function of the ST2 gene in a murine model of allergic airway inflammation. Clin Exp Allergy. 2002;32(10):1520-6. http://dx.doi.org/10.1046/j.1365-2745.2002.01494.x

22. Lopez-Casado MA, Lorite P, Palomeque T, Torres MI. Potential role of the IL-33/ST2 axis in celiac disease. Cell Mol Immunol. 2017;14(3):285-292. http://dx.doi.org/10.1038/cmi.2015.85

23. Tominaga SI, Ohta S, Tago K. Soluble form of the ST2 gene product exhibits growth promoting activity in $\mathrm{NIH}-3 \mathrm{~T} 3$ cells. BiochemBiophys Rep. 2016;(5):8-15. http://dx.doi.org/10.1016/j. bbrep.2015.11.020

24. Martin NT, Martin MU. Interleukin 33 is a guardian of barriers and a local alarmin. Nat Immunol. 2016;17(2):122-31. http:// dx.doi.org/10.1038/ni.3370

25. Cayrol C, Girard JP. IL-33: an alarmin cytokine with crucial roles in innate immunity, inflammation and allergy. CurrOpinlmmunol. 2014;(31):31-7. http://dx.doi.org/10.1016/j.coi.2014.09.004

26. Molofsky AB, Savage AK, Locksley RM. Interleukin-33 in tissue homeostasis, injury, and inflammation. Immunity. 2015;42(6):1005-1019. http://dx.doi.org/10.1016/j. immuni.2015.06.006

27. Lunderius-Andersson C, Enoksson M, Nilsson G. Mast Cells Respond to Cell Injury through the Recognition of IL33. Front Immunol. 2012;(3):82. http://dx.doi.org/10.3389/ fimmu.2012.00082

28. Liew FY, Girard JP, Turnquist HR. Interleukin-33 in health and disease. Nat Rev Immunol. 2016;16(11):676-689. http://dx.doi. org/10.1038/nri.2016.95

29. Martin MU. Special aspects of interleukin-33 and the IL-33 receptor complex. Semin Immunol. 2013;25(6):449-57. http://dx.doi.org/10.1016/j.smim.2013.10.006 
30. Carriere V, Roussel L, Ortega N, Lacorre DA, Americh L, Aguilar L et al. IL-33, the IL-1-like cytokine ligand for ST2 receptor, is a chromatin-associated nuclear factor in vivo. Proc Natl Acad Sci U S A. 2007;104(1):282-7. http://dx.doi.org/10.1073/pnas.0606854104

31. Matta BM, Reichenbach DK, Zhang X, Mathews L, Koehn $\mathrm{BH}$, Dwyer GK et al. Peri-allo HCT IL-33 administration expands recipient T-regulatory cells that protect mice against acute GVHD. Blood. 2016;128(3):427-39. http://dx.doi.org/10.1182/ blood-2015-12-684142

32. Schiering C, Krausgruber T, Chomka A, Fröhlich A, Adelmann $\mathrm{K}$, Wohlfert EA et al. The alarmin IL-33 promotes regulatory T-cell function in the intestine. Nature. 2014;513(7519):564-568. http:// dx.doi.org/10.1038/nature13577

33. Morita H, Arae K, Unno H, Saito H, Matsumoto K, Nakae S et al. An Interleukin-33-Mast Cell-Interleukin-2 Axis Suppresses Papain-Induced Allergic Inflammation by Promoting Regulatory T Cell Numbers. Immunity. 2015;43(1): 175-86. http://dx.doi. org/10.1016/j.immuni.2015.06.021

34. Cohen ES, Scott IC, Majithiya JB, Rapley L, Kemp BP, England $E$ et al. Oxidation of the alarmin IL-33 regulates ST2-dependent inflammation. Nat Commun. 2015;(6):8327. http://dx.doi. org/10.1038/ncomms9327

35. XU D, Jiang HR, Kewin P, Li Y, Mu R, Fraser AR et al. IL-33 exacerbates antigen-induced arthritis by activating mast cells. Proc Natl Acad Sci U S A. 2008; 105(31):10913-8. http://dx.doi. org/10.1073/pnas.0801898105

36. Laperine O, Cloitre A, Caillon J, Huck O, Bugueno IM, Pilet P et al. Interleukin-33 and RANK-L Interplay in the Alveolar Bone Loss Associated to Periodontitis. PLoS One. 2016;11(12):e0168080. http://dx.doi.org/10.1371/journal.pone.0168080

37. Xiangyang Z, Lutian Y, Lin Z, Liping X, Hui S, Jing L. Increased levels of interleukin-33 associated with bone erosion and interstitial lung diseases in patients with rheumatoid arthritis. Cytokine. 2012;58(1):6-9. http://dx.doi.org/10.1016/j. cyto.2011.12.010
38. Tada H, Suzuki R, Nemoto E, Shimauchi H, Matsushita $\mathrm{K}$, Takada $\mathrm{H}$. Increases in IL-33 production by fimbriae and lipopeptide from Porphyromonas gingivalis in mouse bone marrow-derived dendritic cells via Toll-like receptor 2. Biomed Res. 2017;38(3):189-195. http://dx.doi.org/10.2220/ biomedres.38.189

39. Arend WP, Palmer G, Gabay C. IL-1, IL-18, and IL-33 families of cytokines. Immunol Rev. 2008;(223):20-38. http://dx.doi. org/10.1111/j.1600-065X.2008.00624.X

40. Lu HK, Chen YL, Chang HC, Li CL, Kuo MYP. Identification of the osteoprotegerin/receptor activator of nuclear factor-kappa $B$ ligand system in gingival crevicular fluid and tissue of patients with chronic periodontitis. J Periodontal Res. 2006;41(4):354-60. http://dx.doi.org/10.1111/j.1600-0765.2006.00883.x

41. Luz FA, Oliveira APL, Borges D, Brígido PC, Silva MJB. The physiopathological role of IL-33: new highlights in bone biology and a proposed role in periodontal disease. Mediators Inflamm. 2014;(2014):342-410. http://dx.doi.org/10.1155/2014/342410

42. Mun SH, Ko NY, Kim HS, Kim JW, Kim DK, Kim AR et al. Interleukin-33 stimulates formation of functional osteoclasts from human CD14(+) monocytes. Cell Mol Life Sci. 2010;67(22):3883-92 http://dx.doi.org/10.1007/s00018-010-0410-y

43. Papathanasiou E, Teles F, Griffin T, Arguello E, Finkelman N, Hanley J et al. Gingival crevicular fluid levels of interferon-gamma, but not interleukin-4 or -33 or thymic stromal lymphopoietin, are increased in inflamed sites in patients with periodontal disease. J Periodontal Res. 2014;49(1):55-61. http://dx.doi.org/10.1111/ jre.12078 